\title{
Predictive capacity of drug use, impulsivity and sensation-seeking in aggressors and victims of violence
}

\author{
María del Carmen Pérez-Fuentes 1,*, María del Mar Molero Jurado ${ }^{1}$, María del Mar Simón \\ Márquez ${ }^{1}$, and José Jesús Gázquez Linares ${ }^{1,2}$ \\ 1 Department of Psychology, Faculty of Psychology, University of Almería, 04120 Almería, Spain; \\ mmj130@ual.es (M.d.M.M.J.); msm112@ual.es (M.d.M.S.M.); jlinares@ual.es (J.J.G.L.) \\ 2 Department of Psychology, Faculty of Psychology, Universidad Autónoma de Chile, 4780000 Santiago, \\ Chile \\ * Correspondence: mpf421@ual.es; Tel.: +34-950015598
}

\begin{abstract}
Background: The purpose of this study was therefore to analyze the predictive capacity of the three variables (impulsivity, sensation-seeking and drug use) in aggressors and victims of violence. (2) Methods: The design is cross-sectional quasi-experimental. A sample of 822 students aged 13 to 18 who had filled in an ad hoc questionnaire, the State Impulsivity Scale and the Sensation-Seeking Scale, was used for this. (3) Results: The results show that aggressors had high levels of gratification, automatism, attentional factor, disinhibition and susceptibility to boredom, and use alcohol and/or tobacco. The variables that could predict involvement as an aggressor in peer conflict are use of alcohol, smoking, high levels of gratification, automatism and attentional factors and a high degree of disinhibition and susceptibility to boredom. The disinhibition is the best predictor of aggressor. (4) Conclusions: Thus having available empirical evidence that facilitates detection of predictive variables for participation in violence is going to favor the design of effective education intervention for reducing risk behavior.
\end{abstract}

Keywords: drug, impulsivity, sensation-seeking, peer conflict, adolescent.

\section{Introduction}

For years, peer violence, understood as a class of repeated intentional aggression toward another person with whom there is an imbalance of power, and which may be physical, verbal or in interpersonal relations [1], has been one of the most formidable problems in the school environment. Peer violence may increase when students suffer from problems of anxiety or depression at the beginning of the school year [2], which could give them the appearance of being vulnerable and make them easier targets for potential aggressors [3].

This phenomenon has many causes [4-6], and likewise, predisposing factors have been found which would increase the probability of a person becoming involved in school violence. Among some of the most important are low levels of emotional skills in aggressors [7], family characteristics, such as lack of care, supervision, control and parental affect [8-11], and substance use [12-14].

Adolescence is a critical period for development of disorders related to substance abuse [15], as reflected in the State Survey on High School Drug Use, ESTUDES 2016-2017 [16], which shows that alcohol and tobacco continue to be the drugs most used by students from 14 to 18 years old. In addition to these figures, the risk of developing disorders related to alcohol abuse is twice as high for adolescents as for young adults and seven times higher for young people aged 15 to 16 compared to young adults 22 to 26 years old in the case of disorders related to cannabis [17]. 
Drug use has a more complex relationship than simply favoring the appearance of bullying. It has been found that there is a stronger tendency toward substance use and abuse in young people who were aggressors during adolescence [18]. Paradoxically, this also is the case of victims, whose probability of using substances increases [19]. In this respect, an apparently contradictory fact is found in that adolescents who smoke cigarettes, marihuana or drink alcohol have less probability of being victims of bullying [20]. Such results show the obvious relationship between substance use and problematic, maladaptive or risk behavior [21].

Impulsivity, a trait which has also been described as a factor predisposing to participation in violence, characterizes aggressors or bullies [22], and is also associated with other behaviors, such as substance use, for which high school students who said they had drunk alcohol or smoked at some time or did so habitually scored significantly higher [23]. Dysfunctional impulsivity [24] has specifically been shown to be a construct with a close relationship to addiction [25]. Preliminary studies have analyzed whether this is the cause or the consequence of substance use and abuse behaviors, a matter mentioned above, and the results seem to indicate that in the aggressor or bully profile, substance use promotes aggressive behavior toward others [26,27], and is also related to school failure. This, in turn, is a vulnerability factor for substance use and polyuse, as well as for antisocial behaviors [28].

Sensation-seeking as a personality trait is the search for new, different, complex and intense sensations and experiences, and the tendency to behavior placing physical health, social, legal and economic situations at risk to achieve the satisfaction of such experiences [29]. Impulsivity and sensation-seeking are some of the personality factors relevant to the appearance of risk behaviors [30]. Sensation-seeking also has an important role in the dynamics of bullying, such as substance use. In the eighties, it was already found that excessive alcohol intake was strongly related to sensationseeking, resulting in a more obvious relationship for abuse than for use [31]. This has been replicated in more recent research [32,33]. Furthermore, Kirsch [34] found that subjects with high sensationseeking traits felt more attracted by violent images, which has also been associated with different forms of aggression and the possibility of becoming involved in cyberbullying [35]. Such data, although they show the relationship between sensation-seeking and violent behaviors, are insufficiently specific to come to conclusions on whether this construct can predict such violent behavior among peers, and this is one of the objectives this study intended to achieve.

It may therefore be stated that aggressors have certain characteristics, among which the most important are impulsivity [36], hyperactive behavior patterns [37], low academic performance often leading to the student repeating a year [38], low levels of benevolence [39], and a strong tendency to be distracted or limited prosocial interaction [40]. This further influences academic performance negatively, as it has been found that high scores in prosocial behavior in high school students favors attitude, motivation exam preparation strategies, etc. [41].

On the contrary, the victims usually have a lower level of self-esteem [42, 43], specific needs for educational support [44], feelings of unhappiness, rejection by their peer group, anxiety and depression [45], which can lead to the student's having depressive episodes [46]. When coping with bullying, victims are characterized by trying to get out of the situation repeatedly and in different ways, but unsuccessfully, which seems to indicate that they do not develop adequate resources enabling them to end the abuse [47]. The impulsivity, sensation-seeking and drug use variables have been found to be closely related. They in turn also have a close relationship with peer conflict. The objective of this study was to analyze the predictor capacity of these three variables (impulsivity, sensation-seeking and drug use) in peer conflict and violence.

Based on prior empirical evidence, the following hypotheses are posed: 1) aggressors have higher scores in traits associated with impulsivity and sensation-seeking than non-aggressors, 3) victims show differences from non-victims, in their lower impulsivity and sensation-seeking scores, and 4) 
impulsivity traits, the tendency to sensation-seeking and drug and tobacco use are predictors of involvement of the participants in episodes of peer violence.

\section{Materials and Methods}

\subsection{Participants}

The sample was taken by random cluster sampling by the geographic zones into which the city of Almeria is divided, for which eight high schools were selected at random. The size of the starting sample size was set at 906 for a 3.2\% confidence interval, with a $95 \%$ confidence level and 0.5 population variance. Twenty-three questionnaires were disqualified because of a systematically inconsistent response pattern for the questions asked, and 61 were discarded because they were incomplete. Thus the final sample consisted of 822 students from $3^{\text {rd }}$ and $4^{\text {th }}$ year high school, with an age range of 13 to 18 and a mean of 14.84 years $(S D=.87)$. Of the total sample, $51.8 \%(N=426)$ were males and $48.2 \%(N=396)$ females, with mean ages of $14.85(S D=.87)$ and 14.82 years $(S D=.86)$, respectively. The grade distribution of the sample was the following: $43.7 \%$ were in $3^{\text {rd }}$ year $(N=359)$ and the other $56.3 \%$ were in $4^{\text {th }}$ year $(N=463)$.

\subsection{Instruments}

An questionnaire to find out the sociodemographic characteristics of the participants, whether aggressor (Have you ever used/do you use violence against your fellow students?) or victim (Have you ever been the object of violence by your fellow students?) [38], and items in which they were asked about their drinking alcohol (How often do you drink alcoholic beverages (glasses/drinks)? and tobacco (How often do you smoke cigarettes?) [48].

State Impulsivity Scale by Iribarren, Jiménez-Giménez, García-de Cecilia \& Rubio-Valladolid [49]. This scale was designed to evaluate the impulsive behavior defined as state, that is impulsivity as a manifest behavior which can vary in the short term. It consists of 20 items, distributed into three subscales: Gratification (evaluates the urgency in satisfying impulses, preference for immediate reward, intolerance of frustration and the tendency to act without thinking about any negative consequences; Automatism (refers to behavior expressed rigidly and repeatedly, without paying attention to contextual variables); and Attentional (evaluates the presence of unplanned behaviors which take place because of having acted too soon and without considering all the information available). The response is based on a four-point Likert scale where the participants are asked to evaluate the frequency with which each of the statements is their case. The authors [49] found high reliability for both the total scale $(\alpha=.88)$ and each of its dimensions: Gratification $(\alpha=.84)$, Automatism $(\alpha=.80)$ and Attentional $(\alpha=.75)$.

Sensation-Seeking Scale [50]. Its 40 yes/no response items evaluate the trait for seeking new risky experiences. It is comprised of four subscales: Emotion-seeking (EMS), Excitement-seeking (EXS), Disinhibition (DIS) and Susceptibility to Boredom (STB).

\subsection{Procedure}

The design is cross-sectional quasi-experimental. First, the directors of each school were informed of the objectives, procedure and use of data for research. In addition, parents/guardians were asked for the pertinent permission on an informed consent sheet. Before the tests were administered, the participants were given instructions on how to fill them out and were guaranteed the confidentiality of data processing. Then two members of the research team went to the schools to administer the tests. This was done by standardized anonymous self-reported questionnaire filled out in writing (paper and pencil) by all the participants in a single $40-45$ minute session. 


\subsection{Data analysis}

The Chi Square test was used for bivariate analyses to analyze participant differences. To analyze the predictive capacity of the impulsivity and sensation-seeking traits for being an aggressor or not or being a victim or not, univariate logistic regression models and multivariate binary logistic regression analyses were applied using the forward stepwise regression based on the Wald test with the criterion variables (aggressor and victim) and the nine predictor variables (alcohol use, tobacco use, gratification, automatism, attentional, emotion-seeking, excitement seeking, disinhibition and susceptibility to boredom). Finally, a nonlinear predictive Chi-square Automatic Interaction Detector (CHAID) regression and classification tree were constructed for being an aggressor or not.

For the use variables (alcohol/tobacco), it was unnecessary to set a threshold, since grouping was by whether this characteristic was given or not. However, identification of the criterion for defining sample thresholds (high and low) for interpersonal value scales, normal distribution on the State Impulsivity and Sensation-Seeking questionnaires was tested. The total sample was divided into two groups for each of the scales based on the Gratification, Automatism and Attentional scores: a) subjects with low scores who scored the same or lower than the $25^{\text {th }}$ percentile (scores equal to or higher than 10, 9 and 11, respectively); b) subjects with high scores, who scored the same or higher than the $75^{\text {th }}$ percentile (scores the same or higher than 16, 14 and 17, respectively). For sensationseeking, on the Emotion-Seeking, Excitement-Seeking, Disinhibition and Susceptibility to Boredom scales: a) subjects with low scores who scored the same or lower than the $25^{\text {th }}$ percentile (scores the same or higher than 4, 4, 3 and 3, respectively); b) subjects with high scores who scored the same or higher than the $75^{\text {th }}$ percentile (scores the same or higher than $8,6,6$ and 6 , respectively).

\section{Results}

Table 1 shows the sample distribution with the differences between aggressor and non-aggressor groups. There is a higher presence of aggressors among those with high gratification $(17.1 \%)$, high automatism (14.6\%) and attentional (15\%) compared to low levels $(5.2 \%, 6.3 \%$ and $5.1 \%$, respectively), differences which were significant $(p<.01)$ in all cases. Furthermore, in the analysis of the sensationseeking dimensions, there was a higher prevalence of aggressors among participants who had high disinhibition $(17.5 \%)$ and susceptibility to boredom $(13 \%)$, with significant differences $(p<.01)$ from low scores (4.2\% and $5.9 \%$, respectively).

A majority frequency of aggressors who use alcohol (15.9\% and tobacco (11.8\%) was observed, with statistically significant differences $(p<.01)$ in both cases

Table 1. Aggressor/Non-Aggressor Percentages

\begin{tabular}{|c|c|c|c|c|c|}
\hline & & $\begin{array}{l}\text { Non- } \\
\text { aggressor }\end{array}$ & Aggressor & $x^{2}$ & $p$ \\
\hline \multirow{2}{*}{ Use alcohol } & No & $92.7 \%$ & $7.3 \%$ & \multirow{2}{*}{14.38} & \multirow{2}{*}{.00} \\
\hline & Yes & $84.1 \%$ & $15.9 \%$ & & \\
\hline \multirow{2}{*}{ Use tobacco } & No & $94.1 \%$ & $5.9 \%$ & \multirow{2}{*}{7.26} & \multirow{2}{*}{.01} \\
\hline & Yes & $88.2 \%$ & $11.8 \%$ & & \\
\hline \multirow{2}{*}{ GRA } & Low & $94.8 \%$ & $5.2 \%$ & \multirow{2}{*}{16.82} & \multirow{2}{*}{.00} \\
\hline & High & $82.9 \%$ & $17.1 \%$ & & \\
\hline \multirow{2}{*}{ AUTO } & Low & $93.7 \%$ & $6.3 \%$ & \multirow{2}{*}{9.86} & \multirow{2}{*}{.01} \\
\hline & High & $85.4 \%$ & $14.6 \%$ & & \\
\hline \multirow{2}{*}{ ATEN } & Low & $94.9 \%$ & $5.1 \%$ & \multirow{2}{*}{13.61} & \multirow{2}{*}{.00} \\
\hline & High & $85 \%$ & $15 \%$ & & \\
\hline \multirow{2}{*}{ EMS } & Low & $90.4 \%$ & $9.6 \%$ & \multirow{2}{*}{.25} & \multirow{2}{*}{.61} \\
\hline & High & $89 \%$ & $11 \%$ & & \\
\hline
\end{tabular}




\begin{tabular}{|c|c|c|c|c|c|}
\hline \multirow{2}{*}{ EXS } & Low & $92.1 \%$ & $7.9 \%$ & \multirow{2}{*}{1.39} & \multirow{2}{*}{.24} \\
\hline & High & $92.1 \%$ & $7.9 \%$ & & \\
\hline \multirow{2}{*}{ DIS } & Low & $95.8 \%$ & $4.2 \%$ & \multirow{2}{*}{25.69} & \multirow{2}{*}{.00} \\
\hline & High & $82.5 \%$ & $17.5 \%$ & & \\
\hline \multirow{2}{*}{ STB } & Low & $94.1 \%$ & $5.9 \%$ & \multirow{2}{*}{7.78} & \multirow{2}{*}{.01} \\
\hline & High & $87 \%$ & $13 \%$ & & \\
\hline
\end{tabular}

Note: GRA= Gratification; AUTO= Automatism; ATEN= Attentional; EMS= Emotion-seeking; EXS= Excitement-seeking; DIS= Disinhibition; $\mathrm{STB}=$ Susceptibility to Boredom.

The same analysis done for victims and non-victims (Table 2) shows that even though the differences are not statistically significant, higher prevalence of victims may be observed among those who have low levels of Gratification (11.3\%), Attentional (9.3\%), Disinhibition (12.1\%) and Susceptibility to Boredom (10.5\%), and a higher frequency of victims among those who have high scores in Automatism (13.4\%), Emotion-seeking (10.7\%) and Excitement-seeking (11\%). By use of alcohol or tobacco, no significant differences were observed in the frequency of victims/non-victims.

Table 2. Percentages of victims/non-victims

\begin{tabular}{|c|c|c|c|c|c|}
\hline & & Non-victim & Victim & $x^{2}$ & $p$ \\
\hline \multirow{2}{*}{ Use alcohol } & No & $90.1 \%$ & $9.9 \%$ & \multirow{2}{*}{1.38} & \multirow{2}{*}{.24} \\
\hline & Yes & $87.3 \%$ & $12.7 \%$ & & \\
\hline \multirow{2}{*}{ Use tobacco } & No & $89 \%$ & $11 \%$ & \multirow{2}{*}{.03} & \multirow{2}{*}{.85} \\
\hline & Yes & $89.4 \%$ & $10.6 \%$ & & \\
\hline \multirow{2}{*}{ GRA } & Low & $88.7 \%$ & $11.3 \%$ & \multirow{2}{*}{.06} & \multirow{2}{*}{.81} \\
\hline & High & $89.4 \%$ & $10.6 \%$ & & \\
\hline \multirow{2}{*}{ AUTO } & Low & $91.5 \%$ & $8.5 \%$ & \multirow{2}{*}{3.26} & \multirow{2}{*}{.07} \\
\hline & High & $86.6 \%$ & $13.4 \%$ & & \\
\hline \multirow{2}{*}{ ATEN } & Low & $90.7 \%$ & $9.3 \%$ & \multirow{2}{*}{.02} & \multirow{2}{*}{.89} \\
\hline & High & $91 \%$ & $9 \%$ & & \\
\hline \multirow{2}{*}{ EMS } & Low & $89.5 \%$ & $10.5 \%$ & \multirow{2}{*}{.01} & \multirow{2}{*}{.96} \\
\hline & High & $89.3 \%$ & $10.7 \%$ & & \\
\hline \multirow{2}{*}{ EXS } & Low & $91 \%$ & $9 \%$ & \multirow{2}{*}{.63} & \multirow{2}{*}{.43} \\
\hline & High & $89 \%$ & $11 \%$ & & \\
\hline \multirow{2}{*}{ DIS } & Low & $87.9 \%$ & $12.1 \%$ & \multirow{2}{*}{1.25} & \multirow{2}{*}{.26} \\
\hline & High & $90.9 \%$ & $9.1 \%$ & & \\
\hline \multirow{2}{*}{ STB } & Low & $89.5 \%$ & $10.5 \%$ & \multirow{2}{*}{.02} & \multirow{2}{*}{.90} \\
\hline & High & $89.9 \%$ & $10.1 \%$ & & \\
\hline
\end{tabular}

Note: GRA= Gratification; AUTO= Automatism; ATEN= Attentional; EMS= Emotion-seeking; EXS= Excitement-seeking; DIS= Disinhibition; $\mathrm{STB}=$ Susceptibility to Boredom.

As shown in Table 3, the variables which can predict involvement as an aggressor in peer conflict are drinking alcohol and smoking, with high levels in the gratification, automatism and attentional factors, as well as high disinhibition and susceptibility to boredom.

Table 3. Univariate logistic regression for the probability of being an aggressor

\begin{tabular}{llllllll}
\hline Total & $\boldsymbol{B}$ & SE & Wald & $\boldsymbol{p}$ & OR & IC & $\begin{array}{l}\boldsymbol{R}^{2} \\
\text { Nagelkerke }\end{array}$ \\
\hline Use alcohol & .70 & .28 & 6.19 & .01 & 2.02 & $1.16-3.52$ & .02 \\
\hline Use tobacco & .85 & .24 & 13.14 & .00 & 2.35 & $1.48-3.73$ & .03 \\
\hline GRA & 1.31 & .34 & 15.15 & .00 & 3.72 & $1.92-7.20$ & .07 \\
\hline
\end{tabular}




\begin{tabular}{lllllllll}
\hline AUTO & .96 & .31 & 9.94 & .01 & 2.61 & $1.44-4.75$ & .04 \\
\hline ATEN & 1.19 & .34 & 12.44 & .00 & 3.30 & $1.70-6.41$ & .06 \\
\hline DIS & 1.59 & .34 & 21.97 & .00 & 4.88 & $2.52-9.48$ & .10 \\
\hline STB & .81 & .31 & 6.72 & .01 & 2.26 & $1.22-4.18$ & .03 \\
\hline
\end{tabular}

Note: GRA= Gratification; $\mathrm{AUTO}=$ Automatism; ATEN= Attentional; EMS= Emotion-seeking; EXS=

Excitement-seeking; DIS= Disinhibition; $\mathrm{STB}=$ Susceptibility to Boredom. $\mathrm{B}=$ coefficient; $\mathrm{SE}=$ standard error; $\mathrm{OR}=$ odd ratio; $\mathrm{CI}=$ confidence interval at $95 \%$.

As observed in the decision tree (Figure 1), the disinhibition is the best predictor of agressor. Participants with lower scores in Disinhibition and in Gratification have a lower probability of being agressor $(97 \%)$. The greatest risk of being an aggressor $(27,8 \%)$ is among those who have higher scores in Disinhibition. The goodness of fit of model functioning can be observed in its correct classification of $90 \%$ of the participants.

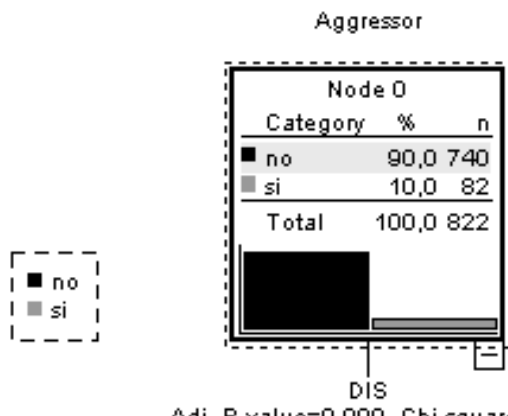

Adj. P-value $=0,000$, Chi-square $=41$

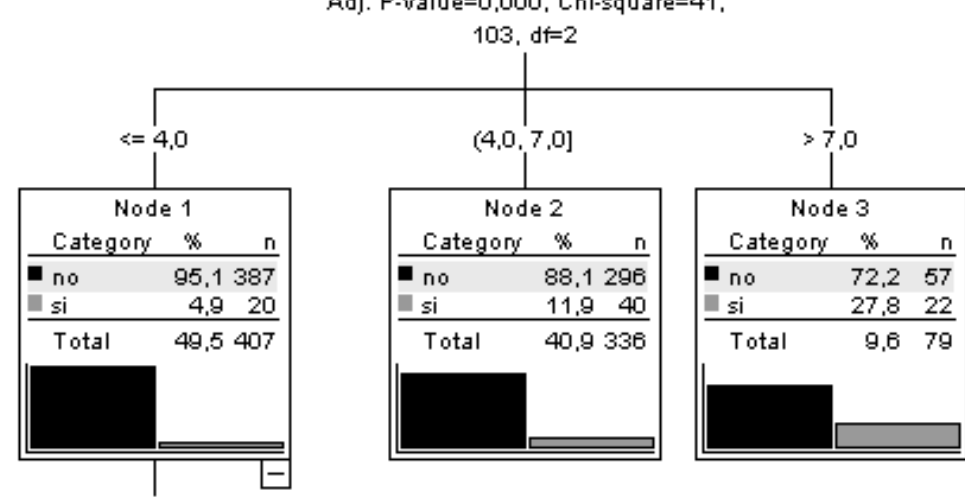

Adj. P-value $=0,002$, Chi-square $=13$,

246. $d f=1$

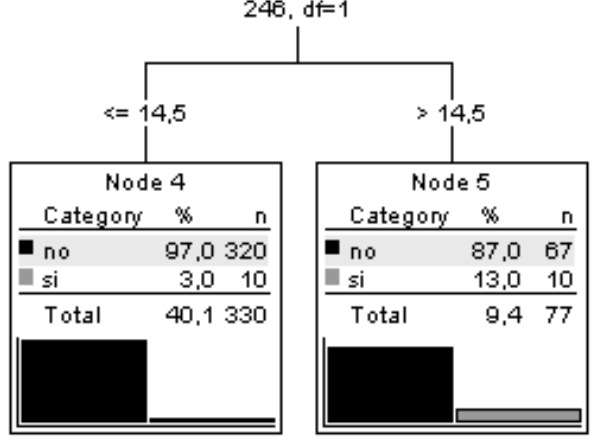

Figure 1. Regression and classification tree Aggressor 
The aspects which showed association with each final objective at $p<.01$ were included in the model in the univariate analysis. Thus the fit by a multivariate logistic regression model which is the correct classification of $22.3 \%\left(R^{2}=.22\right)$, shows the high scores in disinhibition $(O R=11.93$; IC95\%=2.47-57.65) as a variable associated with the aggressor profile (Table 4).

Table 4. Logistic regression for probability of being an aggressor

\begin{tabular}{llllllll}
\hline Total & $\boldsymbol{B}$ & $\boldsymbol{S E}$ & Wald & $\boldsymbol{p}$ & OR & $\boldsymbol{C I}$ & $\begin{array}{l}\boldsymbol{R}^{2} \\
\text { Nagelkerke }\end{array}$ \\
\hline DIS & 2.48 & .80 & 9.52 & .01 & 11.94 & $2.47-57.66$ & .22 \\
\hline
\end{tabular}

Note: DIS= Disinhibition; $\mathrm{B}=$ coefficient; $\mathrm{SE}=$ standard error; $\mathrm{OR}=$ odd ratio; $\mathrm{CI}=$ confidence interval at $95 \%$.

No multivariate model analysis was performed for the victim profile as no association at $p<.01$ was found for any of the variables in the univariate analysis (Table 5).

Table 5. Univariate logistic regression for probability of being a victim

\begin{tabular}{llllllll}
\hline Total & $\boldsymbol{B}$ & $\boldsymbol{E T}$ & Wald & $\boldsymbol{p}$ & $\boldsymbol{O R}$ & $\boldsymbol{I C}$ & $\begin{array}{l}\boldsymbol{R}^{\mathbf{2}} \\
\text { Nagelkerke }\end{array}$ \\
\hline Use alcohol & -.04 & .23 & .03 & .85 & .95 & $.60-1.52$ & .00 \\
\hline Use tobacco & .27 & .23 & 1.37 & .24 & 1.32 & $.83-2.10$ & .00 \\
\hline GRA & -.07 & .29 & .05 & .81 & .93 & $.51-1.67$ & .00 \\
\hline AUTO & .50 & .28 & 3.21 & .07 & 1.66 & $.95-2.90$ & .01 \\
\hline ATEN & -.04 & .31 & .02 & .88 & .95 & $.51-1.76$ & .00 \\
\hline EMS & .01 & .28 & .00 & .95 & 1.01 & $.58-1.77$ & .00 \\
\hline EXS & .21 & .27 & .63 & .42 & 1.24 & $.72-2.11$ & .00 \\
\hline DIS & -.31 & .28 & 1.24 & .26 & .72 & $.41-1.27$ & .00 \\
\hline STB & -.03 & .29 & .01 & .89 & .96 & $.53-1.72$ & .00 \\
\hline
\end{tabular}

Note: $\mathrm{GRA}=$ Gratification; AUTO= Automatism; ATEN= Attentional; EMS= Emotion-seeking; EXS= Excitementseeking; DIS= Disinhibition; $\mathrm{STB}=$ Susceptibility to Boredom. $\mathrm{B}=$ coefficient; $\mathrm{SE}=$ standard error; $\mathrm{OR}=$ odd ratio; $\mathrm{CI}=$ confidence interval at $95 \%$.

\section{Discussion}

In the first place, based on the data from the frequency analysis, a higher percentage of aggressors were found among the subjects who showed high levels of gratification, automatism and attentional factor. Furthermore, a higher frequency of aggressors was observed among the participants in the sample who had higher scores in disinhibition and susceptibility to boredom. In addition, a larger number of aggressors were also found among those who use alcohol and/or tobacco. These initial results already provide clues to the relationship of impulsivity traits [36], the tendency to sensationseeking [34] and substance use $[12,13]$ to the aggressor profile.

School violence victims showed a contrary tendency to the one observed in aggressors although there were no significant differences in the percentages with respect to non-victims: a larger number of victims among the participants with low levels of Gratification, Attentional, Disinhibition and Susceptibility to Boredom. Results such as these suggest the different forms of coping which 
aggressors and victims use in a conflict situation [47]. The literature refers to the difficulty victims have in developing and/or initiating effective resources, which leads to negative effects associated with the coexistence profile they adopt $[42,43,44,46]$.

The disinhibition is the best predictor of aggressor. The logistic regression analysis provided additional empirical evidence in support of the association of certain impulsivity and sensationseeking traits and alcohol and tobacco use and their predictive value for involvement in aggressive behaviors with peers at school. Specifically, the tendency to impulsive behavior (with high levels in the gratification, automatism and attentional factors) has already been proposed as a factor which predisposes to active participation in episodes of violence [22]. Substance use, which is closely related to impulsivity $[23,25]$, is another of the risk factors that can predict violent behavior by adolescents $[26,27,51]$, and is also a later consequence of having adopted an aggressive profile during adolescence [18]. Finally, sensation-seeking, especially in combination with impulsivity, has an important role in explaining and/or predicting risk behavior, such as substance use [30,32,33], or involvement in bullying at school [35].

\section{Conclusions}

The variables that could predict involvement as an aggressor in peer conflict are use of alcohol, smoking, high levels of gratification, automatism and attentional factors and a high degree of disinhibition and susceptibility to boredom. Thus, having empirical evidence available which facilitates the detection of predictive variables of involvement in acts of violence, the disinhibition is the best predictor of aggressor, is going to enable the design of effective interventions for reducing risk behaviors. And, at the same time, acknowledge the importance of working to acquire coping skills and/or strategies in adolescent conflict situations as an alternative to the use of violence. Thus having available empirical evidence that facilitates detection of predictive variables for participation in violence is going to favor the design of effective education intervention for reducing risk behavior.

Author Contributions: M.d.C.P.F., M.d.M.M.J., M.d.M.S.M., and J.J.G.L. contributed to the conception and design of the review. J.J.G.L. applied the search strategy. All authors applied the selection criteria. All authors completed the assessment of risk of bias. All authors analysed and interpreted data. M.d.M.M.J., M.d.C.P.F., and M.d.M.S.M. wrote this manuscript. M.d.M.M.J., M.d.C.P.F. and J.J.G.L. edited this manuscript. M.d.C.P.F. is responsible for the overall project.

Acknowledgments: The present study was undertaken in collaboration with the Peer violence and alcohol and tobacco use in Secondary Education: an augmented reality program for detection and intervention (Reference: EDU2017-88139-R), funded by the State Research Program, Development and Innovation Oriented to the Challenges of Society, within the framework of the State Plan for Scientific and Technical Research and Innovation, and co-financing with Structural Funds of the European Union. Financing of the Ministry of Education, Culture and Sport for mobility stays (Reference: PRX17 / 00365 and Reference: CAS17 / 00197) to the first two authors, respectively. Part of this work has been developed thanks to the financing of University Teaching Training in Deficit Areas, Gerty Cori Aid, for the help in hiring research staff in predoctoral training, granted by María del Mar Simón Márquez

Conflicts of Interest: The authors declare no conflict of interest.

\section{References}

1. Olweus, D. Bullying at school. Blackwell: Oxford, England, 1993.

2. Fekkes, M.; Pijpers, F.I.; Fredriks, A.M.; Vogels, T.; Verloove-Vanhorick, S.P. Do bullied children get ill, or do ill children get bullied? A prospective cohort study on the relationship between bullying and healthrelated symptoms. Pediatrics 2006, 117, 1568-1574. DOI: 10.1542/peds.2005-0187 
3. Crick, N.R.; Casas, J.F.; Ku, H.C. Relational and physical forms of peer victimization in preschool. Dev Psychol 1999, 35, 376-385.

4. Bohnert, A.M.; Crnic, K.A.; Lim, K.G. Emotional competence and aggressive behavior in school-age children. J Abnorm Child Psychol 2003, 31, 79-91.

5. Hemphill, S.A.; Kotevski, A.; Tollit, M.; Smith, R.; Herrenkohl, T.I.; Toumbourou, J.W.; Catalano, R.F. Longitudinal predictors of cyber and traditional bullying perpetration in Australian secondary school students. J Adolesc Health 2012, 51, 59-65. DOI: 10.1016/j.jadohealth.2011.11.019

6. Jiménez, T.I.; Estévez, E. School aggression in adolescence: Examining the role of individual, family and school variables. Int J Clin Health Psychol 2017, 17, 197-296. DOI: 10.1016/j.ijchp.2017.07.002

7. Inglés, C.J.; Torregrosa, M.S.; García-Fernández, J.M.; Martínez-Monteagudo, M.C.; Estévez, E.; Delgado, B. Aggressive behavior and emotional intelligence in adolescence. Eur J Educ Psychol 2014, 7, 29-41. DOI: 10.30552/ejep.v7i1.97

8. Dracic, S. Bullying and Peer Victimization. Mater Sociomed 2009, 21, 216-219.

9. Cutrín, O.; Gómez-Fraguela, J.A.; Maneiro, L.; Sobral, J. Effects of parenting practices through deviant peers on nonviolent and violent antisocial behaviours in middle- and late-adolescence. Eur J Psychol Appl Legal Context 2018, 9, 75-82. DOI: 10.1016/j.ejpal.2017.02.001

10. Rodríguez, A.; Revuelta, L.; Sarasa, M.; Fernández, O. The role of parental socialization styles in school engagement and academic performance. Eur J Educ Psychol 2018, 11, 123-139. DOI: 10.30552/ejep.v11i2.226

11. Pérez-Fuentes, M.C.; Molero, M.M.; Barragán, A.B.; Gázquez, J.J. Family Functioning, Emotional Intelligence, and Values: Analysis of the Relationship with Aggressive Behavior in Adolescents. Int J Environ Res Public Health 2019, 16, 478. DOI: 10.3390/ijerph16030478

12. Cerezo, F.; Méndez, I. Aggressors in bullying and disocial behaviours. Eur J Investig Health Psycho Educa 2013, 3, 5-14. DOI: 10.1989/ejihpe.v3i1.19

13. Bender, D.; Lösel, F. Bullying at school as predictor of delinquency, violence and other anti-social behavior in adulthood. Crim Behav Ment Health 2011, 21, 99-106. DOI: 10.1002/cbm.799.

14. Pérez-Fuentes, M.C.; Molero, M.M.; Barragán, A.B.; Gázquez, J.J. Profiles of Violence and Alcohol and Tobacco Use in Relation to Impulsivity: Sustainable Consumption in Adolescents. Sustainability 2019, 11, 651. DOI: $10.3390 /$ su11030651

15. Verdejo-García, A.; Lawrence, A.J.; Clark, L. Impulsivity as a vulnerability marker for substance-use disorders: Review of findings from high-risk research, problem gamblers and genetic association studies. Neurosci Biobehav Rev 2008, 32, 777-810. DOI: 10.1016/j.neubiorev.2007.11.003

16. Ministry of Health, Social Services and Equality. Survey on drug use in secondary education in Spain 2016-2017. Ministry of Health, Social Services and Equality: Madrid, Spain, 2018.

17. Winters, K.C.; Lee, C.Y. Likelihood of developing an alcohol and cannabis use disorder during youth: association with recent use and age. Drug Alcohol Depend 2008, 92, 239-247. DOI: 10.1016/j.drugalcdep.2007.08.005

18. Moore, S.E.; Norman, R.E.; Sly, P.D.; Whitehouse, A.J.; Zubrick, S.R.; Scott, J. Adolescent peer aggression and its association with mental health and substance use in an Australian cohort. J Adolesc 2014, 37, 11-21. DOI: 10.1016/j.adolescence.2013.10.006. 
19. Romaní, F.; Gutierrez, C. Self-report of bullying aggressive and associated factors in high school Peruvian children. Rev Peru Epidemiol 2010, 14, 201-209.

20. García, X.; Pérez, A.; Nebot, M. Factors related to bullying in adolescents in Barcelona (Spain). Gac Sanit 2008, 24, 103-108. DOI: 10.1016/j.gaceta.2009.09.017.

21. Otero, J.M. Drug use and criminal behavior in adolescence. In Detection and prevention in the classroom of adolescent problems; C. Saldaña (Ed.). Pirámide: Madrid, Spain, 2001; pp. 179-212.

22. Pichardo, M.C.; Arco, J.L.; Fernández-Martin, F.D. The relationship between cognitive impulsivity (R-I) and peer abuse or "bullying" in primary education. Anál Modif Conduct 2005, 31, 359-377.

23. Pérez-Fuentes, M.C.; Gázquez, J.J.; Molero, M.M.; Cardila, F.; Martos, A.; Barragán, A.B.; Garzón, A.; Carrión, J.J.; Mercader, I. Adolescent impulsiveness and use of alcohol and tobacco. Eur J Investig Health Psycho Educa 2015, 5, 371-382. DOI: 10.30552/ejihpe.v5i3.138

24. Dickman, S. Functional and dysfunctional impulsivity. Personality and cognitive correlates. J Pers Soc Psychol 1990, 58, 95-102.

25. Pedrero, E.J. Assessment of functional and dysfunctional impulsivity in substance-addicted patients by means of Dickman's Inventory. Psicothema 2009, 21, 585-591.

26. Kaltiala-Heino, R.; Rimpelä, M.; Rantanen, P.; Rimpelä, A. Bullying at school - an indicator of adolescents at risk for mental disorders. J Adolesc 2000, 23, 661-674.

27. Moñino, M.; Piñero, E.; Arense, J.; Cerezo, F. Violence at school and alcohol and tobacco consumption in students of Secondary Education. Eur J Investig Health Psycho Educa 2013, 3, 137-147. DOI: 10.1989/ejihpe.v3i2.31

28. Cerezo, F.; Méndez, I. Social and health risk behaviours in adolescents. Context intervention proposal for a bullying case. An Psicol 2012, 28, 705-719. DOI: 10.6018/analesps.28.3.156001

29. Zuckerman, M. Behavioral expressions and biosocial bases of sensation seeking. Cambridge University Press: Massachusetts, United States, 1994.

30. Rosenbloom, T. Risk evaluation and risky behaviors of high and low sensation seekers. Soc Behav Personal 2003, 31, 375-386. DOI: 10.2224/sbp.2003.31.4.375

31. Cárdenas, C.; Moreno-Jiménez, B. The search for sensations and alcohol intake in adolescence. Rev Psicol Gen Apl 1989, 42, 343-349.

32. 32. Leeman, R.F.; Hoff, R.A.; Krishnan-Sarin, S.; Patock-Peckham, J.A.; Potenza, M.N. Impulsivity, sensation-seeking and part-time job status in relation to substance use and gambling in adolescents. J Adolesc Health 2014, 54, 460-466. DOI: 10.1016/j.jadohealth.2013.09.014

33. Eskandari, H.; Helmi, S. The role of impulsivity, risk-taking, and sensation-seeking in people prone to substance abuse. Appl Psychol 2014, 6, 48-60.

34. Kirsh, S. The effects of video games on adolescents. The overlooked influence of development. Aggress Violent Behav 2003, 8, 377-389. DOI: 10.1016/S1359-1789(02)00056-3

35. Kokkinos, C.M.; Antoniadou, N.; Markos, A. Cyber-bullying: An investigation of the psychological profile of university student participants. J Appl Dev Psychol 2015, 35, 204-214. DOI: 10.1016/j.appdev.2014.04.001 
36. Low, S.; Espelage, D. Conduits from community violence exposure to peer aggression and victimization: Contributions of parental monitoring, impulsivity, and deviancy. J Couns Psychol 2014, 61, 221-223. DOI: 10.1037/a0035207

37. Nabuzoka, D. Teacher ratings and peer nominations of bullying and other behavior of children with and without learning difficulties. Educ Psychol 2003, 23, 307-322. DOI: 10.1080/0144341032000060147

38. Pérez-Fuentes, M.C.; Gázquez, J.J.; Molero, M.M.; Soler, F.J.; Barragán, A.B. Interpersonal values related to aggressor and victim profiles in adolescents. Intern Jour Psych Psychol Therapy 2015, 15, 229-239.

39. Gázquez, J.J.; Sainz, J.; Pérez-Fuentes, M.C.; Molero, M.M.; Soler, F.J. Interpersonal value profiles and analysis of adolescent academic performance and social thinking. Front Psychol 2015, 6(575). DOI: 10.3389/fpsyg.2015.00575

40. Cho, J.; Hendrickson, J.M.; Mock, D.R. Bullying status and behavior patterns of preadolescents and adolescents with behavioral disorders. Education E Treatment of Children 2009, 32, 655-671.

41. Inglés, C.J.; Martínez-González, A.E.; García-Fernández, J.M. Prosocial behavior and learning strategies in a sample of Spanish students of compulsory secondary education. Eur J Educ Psychol 2013, 6, 33-53. DOI: 10.30552/ejep.v6i1.88

42. Malti, T.; Perren, S.; Buchmann, M. Children's peer victimization, empathy, and emotional symptoms. Child Psychiatry Hum Dev 2010, 41, 98-113. DOI: 10.1007/s10578-009-0155-8.

43. Garaigordobil, M.; Martínez-Valderrey, V.; Aliri, J. Self-esteem, empathy and aggressive behavior in adolescent victims of bullying "face-toface". Eur J Investig Health Psychol Educa 2013, 3, 29-40. DOI: 10.30552/ejihpe.v3i1.33

44. Martos, A.; Del Rey, R. Involvement of students with specific needs for educational support in bullying. Apunt Psicol 2013, 31, 183-190.

45. Rigby, K. Consequences of bullying in schools. Can J Psychiatry 2003, 48, 583-590.

46. Jaureguizar, J.; Bernaras, E.; Soroa, M.; Sarasa, M.; Garaigordobil, M. Depressive symptomatology in adolescents and variables associated with the school and clinical context. Psicol Conductual 2015, 23, 245264.

47. Rodríguez, L.N.; Mora-Merchán, J.A. The use of coping strategies and metacognitive skills in situations of bullying and cyberbullying. Eur J Educ Psychol 2014, 7, 121-129.

48. Delegación del Gobierno para el Plan Nacional sobre Drogas / Government Commission for the National Plan on Drugs. State Survey on Drug Use in Secondary Education (ESTUDES) 2014/2015. Ministerio de Sanidad, Servicios Sociales e Igualdad: Madrid, Spain, 2016.

49. Iribarren, M.M.; Jiménez-Giménez, M.; García-de Cecilia, J.M.; Rubio-Valladolid, G. (2011). Validation and Psychometric Properties of the State Impulsivity Scale (SIS). Actas Esp Psiquiatr 2011, 39, 49-60.

50. Pérez, J.; Torrubia, R. Reliability and validity of the Spanish version of the Sensations Search Scale (Form V). Rev Latinoam Psicol 1986, 7-22.

51. Pérez-Fuentes, M.C.; Molero, M.M.; Barragán, A.B.; Gázquez, J.J. (2019). Family Functioning, Emotional Intelligence, and Values: Analysis of the Relationship with Aggressive Behavior in Adolescents. Int. J. Environ. Res. Public Health 2019, 16, 478. DOI: https://doi.org/10.3390/ijerph16030478 